
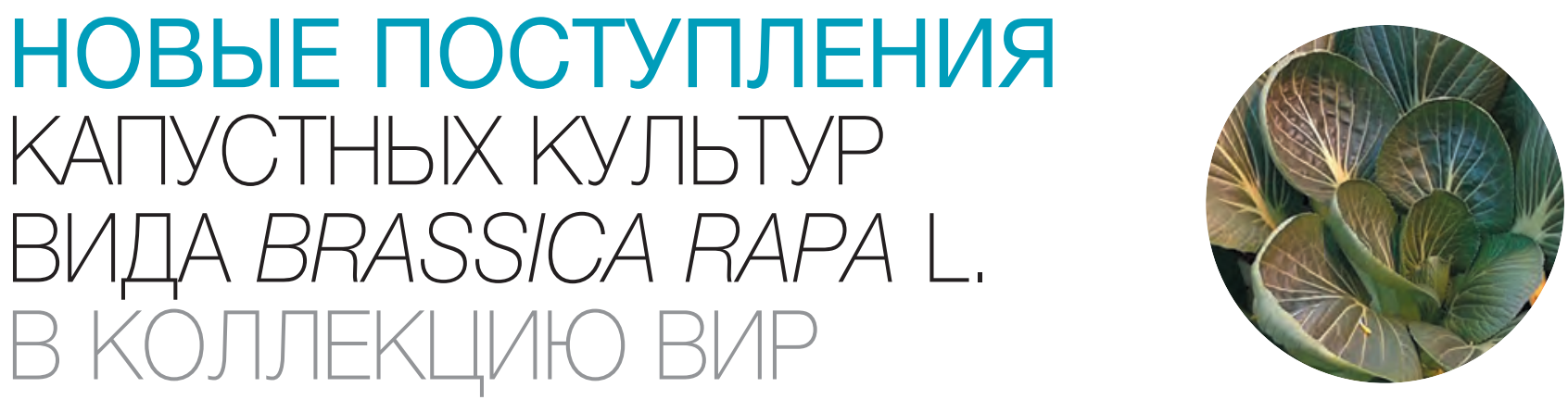

\title{
OF BRASSICA RAPA L. INTO THE VIR PLANT COLLECTION
}

\begin{abstract}
Артемьева А.М. - кандидат сельскохозяйственных наук, ведущий научный сотрудник, руководитель отдела генетических ресурсов овощных и бахчевых культур
\end{abstract}

ФГБНУ «ФИЦ Всероссийский институт генетических ресурсов растений имени Н.И. Вавилова (ВИР)» 190000, Россия, г. Санкт-Петербург, ул. Б. Морская, д. 44 E-mail: akme11@yandex.ru

Капустные культуры вида Brassica rapa L. - пекинская, китайская, розеточная, ноздреватая, пурпурная, японская капусты, брокколетто и японские листовые репы комацуна, курона, хирошимана, сирона, мана - скороспелые продуктивные культуры, отличающиеся наличием ценных биохимических соединений, относительно простые в выращивании. Пекинская капуста распространена широко и повсеместно на земном шаре, в открытом и защищенном грунте, остальные культуры возделываются локально, брокколетто - в Италии, а остальные перечисленные культуры - главным образом в странах Юго-восточной Азии, где население использует различные способы их переработки. В России также возделывается в основном пекинская капуста, особенно в промышленном овощеводстве. Китайская и японская капусты, листовая репа комацуна относятся к очень мало распространенным, остальные культуры практически не известны. Однако овощеводы заинтересованы в расширении ассортимента овощных культур, и садоводы-любители страны знают о ценности родственных пекинской капусте азиатских капустных культур. В статье приведен анализ нового генетического материала капустных культур вида репа Brassica rapa L., привлеченного в коллекцию BИР в последние годы: были привлечены представители всех ботанических подвидов и разновидностей листовых овощных культур. Описаны новые для России культуры розеточная и пурпурная капусты и брокколетто, а также типы сортов, отсутствующие в Госреестре РФ. По результатам изучения в Пушкинских лабораториях ВИР (СанктПетербург) выделены источники продуктивности, скороспелости, устойчивости к болезням, ценного биохимического состава.

Ключевые слова: Brassica rapa L., коллекция BИP, источники ценных признаков.
Artemieva A.M.

Federal Research Centre N.I. Vavilov Institute

of Plant Genetic Resources (VIR)

190000, Russia, Saint-Petersburg, B. Morskaya St, 42-44

E-mail: akme11@yandex.ru

The crops of Brassica rapa L. species are varieties such as pak-choi, tatsoi, wutacai, tsoisum, mizuna, mibuna, brokkoletto and Japanese leafy turnips Komatsuna, Kurona, Hiroshimana, Shirona, Mana, which are all characterized by early-ripening, high productivity, presence of valuable biochemical compounds and relatively simple growing requirements. The nappa cabbage is widespread and cultivated everywhere in the world as open field and greenhouse crop. Other varieties are grown locally, namely brokkoletto is grown in Italy, whereas other mentioned varieties are mostly cultivated in the Southeast Asian countries, where population uses them for different processing technologies. There is the nappa cabbage that is mostly cultivated, particularly for industrial production in Russia. The Chinese cabbage (pak choi), Japanese cabbage, Japanese mustard spinach or Komatsuna are not very widespread and practically unknown crop. However, vegetable growers are interested in using new cole crops, and gardeners know about values of related varieties of nappa cabbage in the group of Asian cole crops. The analysis of incoming genetic accessions of Brassica rapa L. crops that have been included into the VIR plant collection is given. All botanical subspecies and varieties of leafy varieties have been taken for the study. The detailed description of new for Russia varieties, such as purple, brokkoletto, rosette pakchoi as well as well as types of cultivars that haven't still included into State Register of Breeding Achievements of Russian Federation are given. According to research results obtained at Pushkin VIR laboratories (Saint-Petersburg) the initial breeding accessions have been selected to be sources of such characteristics as productivity, early-ripening, disease resistance and valuable biochemical compounds.

Keywords: Brassica rapa L., the VIR plant collection, sources of valuable traits. 
апустные культуры вида Brassica rapa L. - пекинская, китайская, розеточная, ноздреватая, пурпурная, японская капусты, брокколетто и японские листовые репы комацуна, курона, хирошимана, сирона, мана - скороспелые продуктивные культуры, отличающиеся наличием ценных биохимических соединений, относительно простые в выращивании. Капуста пекинская распространена широко и повсеместно на земном шаре, в открытом и защищенном грунте, остальные культуры возделываются локально, брокколетто - в Италии, а остальные перечисленные культуры - главным образом в странах Юго-восточной Азии, где население использует различные способы их переработки.

В России также возделывается в основном капуста пекинская, особенно в промышленном овощеводстве. Китайская и японская капусты, листовая репа комацуна относятся к очень мало распространенным, остальные культуры практически не известны. Однако овощеводы заинтересованы в расширении ассортимента овощных культур, и садоводы-любители страны знают о ценности родственных капусте пекинской азиатских капустных культур.

В 2017 году в Госреестр селекционных достижений РФ включено 76 сортов и гиб- ридов азиатских капустных культур, в т.ч. среди образцов капусты пекинской 76\% гибридов, из которых половина - отечественной селекции, капусты китайской 35\% гибридов [2]. Пекинская капуста представлена в большинстве своем кочанными формами типа Аити (включая подтип Нозаки) и Чифу (включая подтип Мацусима), а также гибридами этих сортотипов с сортами с полуоткрытым кочаном высоких потребительских качеств типа Касин; более половины сортов и гибридов в Госреестре с полуоткрытым кочаном. Достижениями селекции являются гибриды капусты пекинской с генетической устойчивостью к киле и вирусу мозаики турнепса.

Сорта и гибриды капусты китайской, представленные в Госреестре, чаще принадлежат сортотипам Сыюсман (типичный пак-чой, листовая розетка в виде вазы) и Пиорбай с более раскидистой розеткой. Сорт Лебедушка с очень длинным яркобелым черешком относится к сортотипу Тайсай, сорт Аленушка с длинным зеленым черешком - к сортотипу Ютсай (оба селекции ВИР). Сорта Королла и Пава селекции ВИР при включении в Госреестр были условно отнесены к капусте китайской, хотя первый сорт - типичная капуста розеточная (устойчив к сосудистому бактериозу), а второй относится к японским листовым репам формы сирона и выглядит как широколистный гибрид капусты китайской и пекинской с примитивным корнеплодом. Новые сорта селекции ВИР включены в Госреестр в 2017 году как капуста китайская: МЭГГИ - гибрид капусты китайской и розеточной и ВитаВИР гибрид капусты китайской и листовой репы.

Разнообразие капусты японской и листовой репы в Госреестре невелико, в основном эти культуры представлены сортами российской селекции (табл.1). Все сорта капусты японской относятся $\mathrm{K}$ форме мизуна с рассеченным листом, форма мибуна отсутствует; все сорта листовой репы типа комацуна.

Для расширения ассортимента следует создать сорта и гибриды капустных культур, не представленных в Госреестре, а также отсутствующих в нем типов сортов. Особое внимание следует обратить на повышение питательной ценности овощной продукции, повышенное количество биологически активных веществ, которыми богаты малораспространенные капусты. Устойчивость ко всем или нескольким расам сосудистого бактериоза является крайне желательным, хотя и трудно достижимым признаком (3).

Коллекция капустных культур вида репа ВИР включает 944 образца (табл.2).

\section{1. Структура сортов и гибридов пекинской, китайской, японской капусты и листовой репы, входящих} в Государственный реестр селекционных достижений РФ на 2017 год

\begin{tabular}{|l|c|c|c|c|c|}
\hline \multicolumn{1}{|c|}{ Капуста } & Всего & \multicolumn{2}{|c|}{ Количество сортов } & \multicolumn{2}{|c|}{ Количество гибридов } \\
\hline & & всего & отечественные & всего & отечественные, \% \\
\hline пекинская & 50 & 12 & 12 & 38 & 19 \\
\hline китайская & 17 & 11 & 10 & 0 & 0 \\
\hline японская & 5 & 5 & 4 & 0 & 0 \\
\hline листовая репа & 4 & 4 & 3 & 0 \\
\hline
\end{tabular}

2. Состав коллекции капустных культур вида репа Brassica rapa L. BИP

\section{Подвид/разновидность}

\begin{tabular}{|l|l|} 
& Подвид/разновидность \\
\hline капуста пекинская & постоя \\
\hline капуста китайская \\
\hline капуста японская \\
\hline капуста розеточная \\
\hline капуста ноздреватая \\
\hline капуста пурпурная \\
\hline репа листовая \\
\hline брокколетто \\
\hline Картирующие популяции \\
\hline
\end{tabular}

Bсего
Количество образцов в каталоге временном

всего

362

14

3

21

1

479
124

58

486

128

21

15

5

5

59

38

465 


\section{Поступления в коллекцию} капусты в 2007-2016 годах

В 2007-2016 годах в коллекцию капустных культур вида репа были включены 440 образцов, в том числе в результате экспедиционных сборов в Крыму - 3 образца, в Азербайджане - 1, в Таджикистане - 9, в Казахстане - 5, в Киргизии - 25 образцов; из российских селекцентров и селекционных фирм были привлечены 36 образцов, из Украины и Японии по 2 образца, из Финляндии - 1, из США - 28 образцов фирмы Kitazawa Seed, из Китая - 203 образца, в т.ч. из Китайского института овощных и цветочных культур - 30 сортообразцов и 100 линий удвоенных гаплоидов картирующей популяции, из СевероВосточного Университета в Харбине - 30 образцов капусты пекинской кочанной, из Нидерландов - 33 сорта и гибрида, в т.ч. 8 - из генного банка Нидерландов, и 67 линий удвоенных гаплоидов, из европейских генных банков 25 образцов, в т.ч. из Германии - 13, Великобритании - 4, Италии - 8 образцов.

Включен в коллекцию ВИР и изучен в Пушкинских лабораториях ВИР (СанктПетербург) ценный исходный материал для селекции капусты пекинской различных сортотипов. Сортотипы приводятся по [1].

Сортотип Дунганская: местные образцы листовой капусты пекинской из Казахстана и Южной Кореи Местная Чимпа (к-384) и IT 014056 (вр.к-904), с полураскидистой листовой розеткой средней величины, темно-зеленой крупной листовой пластинкой, массой растения 1,45-2,65 кг, относительно устойчивые к раннему стеблеванию, с высоким содержанием аскорбиновой кислоты, каротинов и хлорофиллов.

Сортотип Сяо: полукочанные образцы Далата (Вьетнам, к-245) и к-387 из Китая, отличающиеся компактной листовой розеткой средней величины и мелкой. Полукочан овальный и узкоовальный с открытой вершиной, рыхлый и средней плотности. Масса растения первого сорта 0,8-1,0 кг, полукочана 0,6-0,7 кг, второго сорта соответственно 1,7-2,0 кг и 1,1-1,4 кг. Период вегетации 50-65 суток, устойчивы к стеблеванию.

Сортотип Шантунг: полукочанные скороспелые образцы Тжун Бе (к-321, Китай) и Нагаока Адзума (к-359, Япония) с мелкой и средней величины листовой розеткой, японский сорт без опушения, широ- коовальным кочаном с расширенной открытой вершиной (высота 21-27 см, диаметр 7-12 см). Масса растения 0,9-1,4 Кг, масса кочана 0,7-1,1кг. Относительно устойчивы к стеблеванию, японский сорт устойчив к вирусу мозаики турнепса.

Подтип Санто: Shirokuki Santousai из Японии (к-410) - скороспелый, эффектный, с крупной высокой розеткой, фестончатым надрезанным краем листа, без опушения. Полукочан высокий овальный с расширенной вершиной (высота 3550 см, диаметр 8-18 см), рыхлый, массой 0,9-1,5 кг. Хорош для выращивания в открытом и защищенном грунте.

Сортотип Касин: к сортотипу принадлежат красивейшие сорта капусты пекинской с открытой отбеленной или желтой вершиной плотного кочана, компактной розеткой, пузырчатым нежным листом без опушения или со слабым опушением, скороспелые, устойчивые к стеблеванию, но часто недостаточно устойчивые к альтернариозу и вирусу мозаики турнепса. Таковы образцы из Китая - Тепличная 1 (к-504) кочан высотой 20-24 см, диаметром 7-11 см, массой 0,6-1,3 кг; №94-3 (к-540): кочан высотой 18-30 см, диаметром 12-15 см, массой 0,6-1,0 кг. Особенно выделяются сорта с крупной нарядной розеткой, ярко-желтой вершиной плотного и очень плотного кочана, имеющего тонкую внутреннюю структуру: Тепличная 56 (к-578) - кочан высотой 21-31 см, диаметром 7-12 см, массой 0,9-2,2 кг и вр.к-1096 (возможно, гибрид Касин х Дацинкоу) - кочан высотой 30-33 см и диаметром 10-14 см, массой 1,1-1,7 кг, а также гибриды Касин х Нозаки Xiaoza 60 Bai cai (вp.к-1118) и Beijing Xiaoza 56 (вр.к-1135): скороспелые, с компактной мелкой розеткой, овальным кочаном высотой 22-25 см, диаметром 10-14 см, массой 0,7-0,9 кг. В полевых испытаниях на естественном фоне Ленинградской области эти последние сорта болезнями не поражались.

Сортотип Чосен: близок сортотипу Касин, вершина кочана открытая, менее яркая, часто неотбеленная; сорта чаще корейского происхождения; это один из лучших сортотипов для приготовления кимчи. Выделяются сорта из Южной Kopen Seoul baechu (к-313) и Кэсон 1 (вр.к-737), устойчивые к стеблеванию, с кочаном среднеплотным, высотой 25-30 см, диаметром 8-11 см, массой 0,8-0,9 кг, масса всего растения 1,4-2,2 кг.

Сортотип Аити: включает среднеспелые кочанные образцы, часто недостаточно устойчивые к стеблеванию, кочан овальный с расширенной вершиной, закрытый, отбеленный, листья морщинистые и пузырчатые, обычно со слабым опушением. Высоким качеством кочана отличаются образцы из Кореи Spring King $F_{1}(\mathrm{k}-414)$, из США Two seasons $F_{1}(\mathrm{k}-415)$, из Японии Саката $F_{1}$ Хатахикари (вр.к323), и особенно Тепличный 14 из Японии (вр.к-922) с короткоовальным плотным белым кочаном высотой 20-24 см, диаметром 13-18 см, массой 1,1-1,8 кг.

Подтип Нозаки: отличается устойчивостью к стеблеванию. Отличное качество кочана отмечено у среднеранних образцов из Кореи New summer king (K462), Spring Sun $F_{1}$ (к-539), из Китая к-603 и к-605 (масса кочана 1,5-1,9 и 1,3-1,5 кг соответственно), а также у скороспелых салатных гибридов Нозаки х Касин или Чосен из Китая, с мелким кочаном очень нежной структуры, без опушения, для тепличного овощеводства: Тепличная 3 (к479) - масса кочана 0,7-1,3 кг, Новый осенний 8 (к-547) и Оранжевый 9 (к-548) 0,8-1,6 кг, Яровой 4 (к-581) - 0,9-1,2 кг, Яровой 5 (вр.к-913) - масса кочана1,5-2,5 Кг, вр.к-921 - масса 1,1-1,4 кг.

Сортотип Кага: включает среднеспелые образцы с короткоовальным кочаном хорошего качества, но часто с сильным опушением и недостаточно устойчивые $\mathrm{k}$ стеблеванию в условиях Ленинградской области. По комплексу ценных признаков выделились японские гибриды Нагано CR $F_{1}$ Синреи (к-451), Такии $F_{1}$ Кообо (к-455), Taikan Chyuchun (K-459), Kingdom $65 \mathrm{~F}_{1}$ (K491) - масса кочана 1,5-1,9 Кг, Tango $F_{1}$ (вр.к-692), Fall Forcer (вр.к-1092) со слабым опушением и нежным кочаном массой 1,0-1,8 кг.

К сортотипу Хоторен относятся крупные среднеспелые и среднепоздние образцы с широкоовальным кочаном типа «бочонок", здесь находятся источники высокого качества и отличного вкуса. Образцы часто неустойчивы к преждевременному стеблеванию и болезням. Выделился японский гибрид Hatsubaru $F_{1}$ (к-404) - высота плотного кочана 23-27 см, диаметр 15-21 см, масса 1,5-2,4 кг, New Wind $65 F_{1}(k-432)$, Komachi $F_{1} 9 k-$ 542), Yuki $F_{1}$ (к-543), а также китайские образцы Новый 10 (к-549) и Весенний 11 (k-611). 
Сортам сортотипа Чифу характерна савойская пузырчатость и среднее и сильное опушение листьев, кочан остроконечный типа «пуля». Здесь выделился скороспелый образец из Китая вр.к-1094, отличающийся стабильным кочанообразованием и устойчивостью к стеблеванию. Листовая розетка некрупная, компактная, листья с мягким опушением, кочан овальный с острой вершиной, высотой 24-26 см, диаметром 12-14 см, с очень короткой внутренней кочерыгой 3,0-3,5 см, массой 0,9$1,5 \mathrm{~K} \Gamma$.

Подтип Мацусима: включает среднеспелые образцы со сглажено-острой вершиной. Здесь по комплексу признаков выделились китайские образцы Qing Chun (вp.к-1127) и Chun Shin1 (вр.к-1248) и японский образец вр.к-1347, устойчивый к заболеваниям; масса кочана 1,1-1,2 кг.

Сорта сортотипа Гранат - среднепоздние и позднеспелые, с длинными узкими листьями с частым жилкованием и сильным опушением; кочан высоко цилиндрический; чаще неустойчивы к стеблеванию; устойчивы к заболеваниям, требовательны к высокому содержанию кальция. Интерес представляет китайский образец Желтая (к-494) - Гранат х Касин, устойчивый к стеблеванию, с высоким пузырчатым кочаном с отбеленной вершиной, массой 0,8-1,0 кг. Заслуживает внимания среднепоздний японский гибрид 652 $\mathrm{F}_{1}$ (к503), устойчивый к стеблеванию, слабым поражением вирусом мозаики турнепса. Листовая розетка мелкая, компактная, опушение варьирует от слабого до сильного; кочан узкоцилиндрический, высотой 30-39 см, диаметром 7-12 см, среднеплотный, массой 0,9-1,5 кг.

К сортотипу Хэтоу принадлежат сорта, близкие сортотипу Гранат с более нежными листьями со слабым опушением. Здесь обращает на себя внимание китайский образец Zhong Bai 76 (к-560), среднеспелый (период вегетации 55-70 дней), устойчивый к стеблеванию, с листьями без опушения. Кочан цилиндрический, высотой 30-35 см, диаметром 6-11 см, среднеплотный, массой 0,6-1,0 кг.

Сортотип Дацинкоу: включает сорта с цилиндрическим кочаном со слабо расширенной вершиной; опушение нежное или отсутствует; требовательны к высокому содержанию кальция. Сюда относится известный отличный китайский сорт Qing Qing (вр.к-1096). Интерес представляют местные образцы из

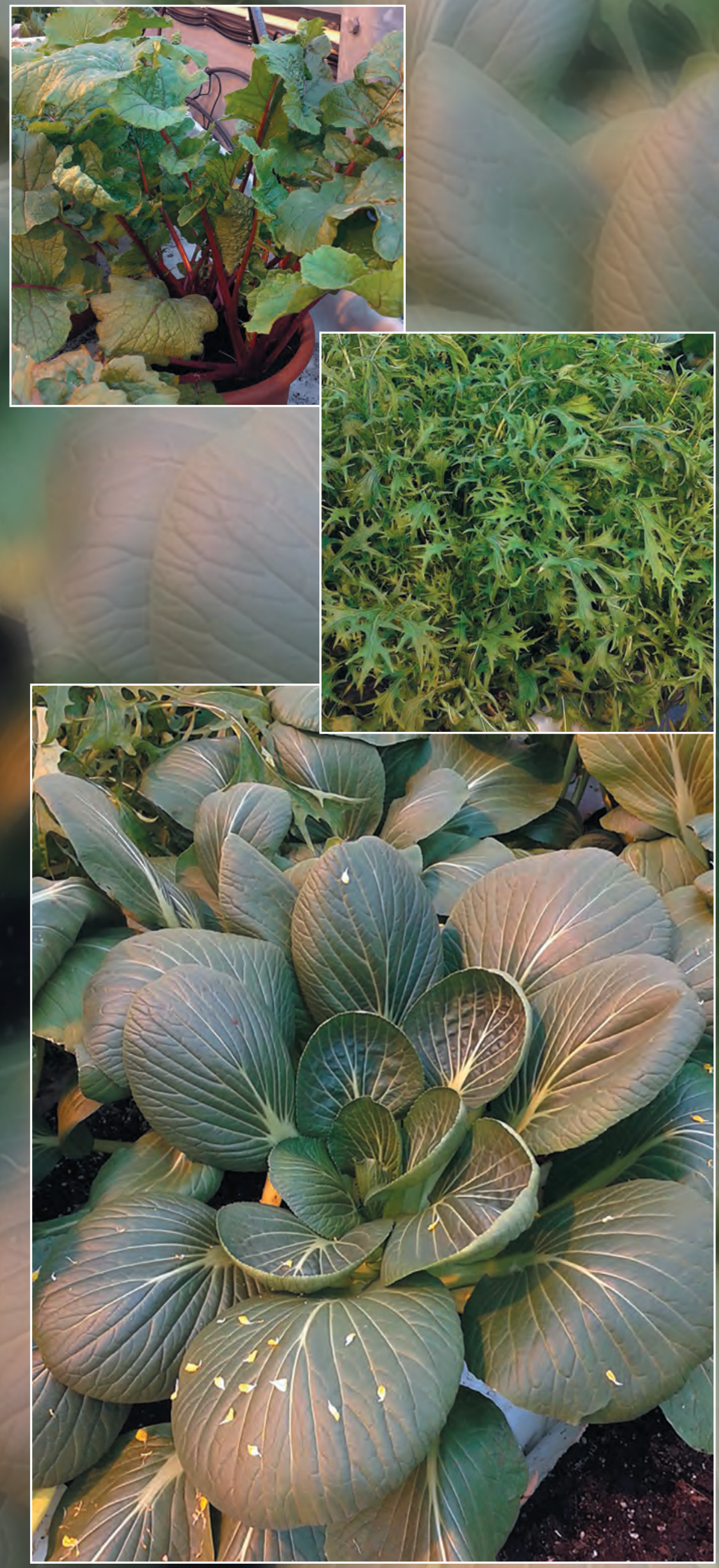




\section{3. Образцы капустных культур, выделившиеся высоким содержанием компонентов} биохимического состава (Пушкин, поле, 2015-2016 годы)

\begin{tabular}{|c|c|c|c|c|c|c|c|}
\hline Каталог & Сорт & $\begin{array}{c}\text { Сухое } \\
\text { вещество, } \\
\%\end{array}$ & $\begin{array}{c}\text { Аскорбиновая } \\
\text { кислота, } \\
\text { мг/100г }\end{array}$ & $\begin{array}{c}\text { Хлорофилл } \\
\text { а, } \\
\text { мг/100г }\end{array}$ & $\begin{array}{c}\text { Хлорофилл } \\
\text { b, } \\
\text { мг/100г }\end{array}$ & $\begin{array}{c}\text { Каротиноиды, } \\
\text { мг/100г }\end{array}$ & $\begin{array}{c}\beta \text {-каротин, } \\
\text { мг/100г }\end{array}$ \\
\hline \multicolumn{8}{|c|}{ Китайская } \\
\hline 203 & Ching Pang Yu Tsai & 8,96 & 48,96 & 143,48 & 59,20 & 29,83 & 5,11 \\
\hline 331 & White Long Petiole & 14,19 & 29,92 & 94,77 & 39,42 & 21,41 & 3,48 \\
\hline вр.1342 & - & 11,24 & 34,00 & 164,07 & 68,46 & 32,77 & 5,68 \\
\hline вp.1343 & Shatu & 9,96 & 34,00 & 163,56 & 68,26 & 29,35 & 5,43 \\
\hline вр.1407 & Purple Choi & 16,11 & 38,12 & 151,99 & 69,29 & 31,95 & 5,62 \\
\hline \multicolumn{8}{|c|}{ Бенрина } \\
\hline 436 & Benrina & 13,81 & 21,76 & 86,61 & 38,31 & 22,91 & 3,53 \\
\hline \multicolumn{8}{|c|}{ Пекинская } \\
\hline 139 & Дунганская & 12,12 & 59,84 & 91,92 & 39,05 & 17,51 & 3,07 \\
\hline 164 & Michihli & 12,44 & 68,00 & 91,56 & 34,63 & 17,80 & 3,04 \\
\hline 338 & Chen-du-ai-u-zai & 16,40 & 27,20 & 103,52 & 43,14 & 18,20 & 3,15 \\
\hline \multicolumn{8}{|c|}{ Розеточная } \\
\hline вр.1398 & Yukina Savoy & 16,04 & 31,28 & 234,13 & 104,48 & 36,12 & 7,91 \\
\hline вр.1409 & Red Tatsoi & 14,04 & 39,44 & 164,09 & 65,39 & 33,46 & 5,64 \\
\hline \multicolumn{8}{|c|}{ Японская } \\
\hline вp.1414 & Green Spray F1 & 13,10 & 38,08 & 161,39 & 53,48 & 36,73 & 5,55 \\
\hline вр.1415 & Early Mibuna & 12,16 & 36,72 & 183,92 & 68,97 & 40,11 & 6,44 \\
\hline
\end{tabular}

Таджикистана вр.к-1316 и вр.к-1317 и из Казахстана вр.к-1327.

Среди образцов капусты китайской самые популярные относятся к сортотипу Сыюсман - типичный пак-чой. Однако, в сортотипе Пиорбай с полураскидистой розеткой и более многочисленными листьями на черешках средней длины, также находятся интересные образцы, устойчивые к заболеваниям и раннему стеблеванию в условиях Ленинградской области, с плотной нежной консистенцией темно-зеленой листовой пластинки и зеленого черешка. Таковы китайские образцы 94 № 4(2) KT33(к-438), 93 № 7 (к-500), Green Boy (к-538), Зеленая 2 (к-612).

Среди образцов сортотипа Сыюсман выделились зеленочерешковые образцы: японский образец Green Petiole (к370), масса растения 0,65-0,9 кг, черешки составляют 70-75\% от массы всего растения, китайские образцы Зеленая 9 (к-529), Xia L V № 2 Pakchoi (к-584), Lingguan № 1 PC (к-585).

Заслуживают внимания, особенно для выращивания в тепличном овощеводстве, образцы мини-пак-чой, скороспелые, с очень мелкой компактной розеткой в форме вазы: Mei Qing Choi (к-470, Япония), китайские образцы Shanghai dwarf green (к-319), Kangra 605 (вр.к-1131), вр.к-1349, вр.к-1353.

Сортотип Ютсай включает образцы капусты китайской с очень темно-зеленой листовой пластинкой и зеленым длинным черешком; листья многочисленные, косо вверх направленные. Сорта устойчивы к раннему стеблеванию, отличаются очень ценным биохимическим составом. Среди новых поступлений это китайские образцы Shatu (вр.к-1343), вр.к-1319, вр.к-1342; масса растения 04,-1,3 кг.

Сортотип Лей-чой представлен, вероятно, гибридами между образцами сортотипов Ютсай и Сыюсман. Им свойственны толстые ярко-белые черешки блестящих темно-зеленых лировидных и неясно-лировидных листьев, высокая продуктивность, устойчивость к стеблеванию: Joi Choi $\mathrm{F}_{1}$ (к-558, Япония), Lei choi (вp.к-785, США).

Розеточная капуста (плоская капуста, черная китайская капуста): сорта с плоской сильно облиственной листовой розеткой малых и очень малых разме- ров, декоративной, похожей на цветок. Листья очень темно-зеленые, блестящие, крупнопузырчатые, загнуты книзу капюшонообразно. Низкоурожайные, часто неустойчивы к стеблеванию, имеют ценный биохимический состав. Новые китайские образцы отличаются очень мелкой прижатой листовой розеткой диаметром 20-30 см и устойчивостью к стеблеванию: Зеленая 4 (к-

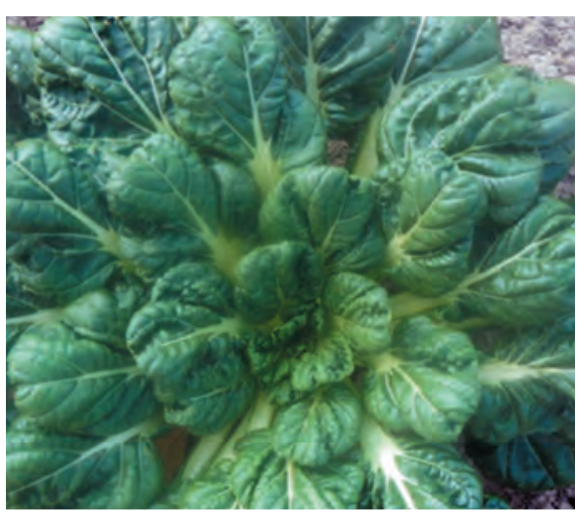

552), Wutacai (вp.k-1111), Xiao Ba Ye Ta Cai (вр.к-1126).

Рис. Капуста розеточная Королла. Продуктовый орган - розетка темно-зеленых листьев, похожая на цветок. Период вегетации 45 суток. Для открытого грунта. Масса растения 0,3-0,6 кг. Устойчив к стеб- 
леванию. Исключительно ценный химический состав. Декоративность высокая.

Капуста японская Мизуна наряду с пищевыми достоинствами отличается высокой декоративностью и устойчивостью к стеблеванию. Среди новых поступлений интересен китайский образец Xiye xuelihong (вр.к-1112) с высокой облиственностью, очень сильным рассечением узкой листовой пластинки (масса растения 0,6-0,8 кг).

Капуста японская Мибуна имеет длинно-ланцетные многочисленные листья, она также весьма декоративна. Интересен японский образец Mibuna Nakate (вр.к-838) с крупной сильно облиственной розеткой, масса которой 0,7-0,8 кг

Капуста пурпурная: черешки листьев темно-красные, иногда с фиолетовым оттенком, листовая пластинка темнокрасно-зеленая. Растение скороспелое (период вегетации 25-35 дней), неустойчивое к стеблеванию, низкоурожайное. Диаметр листовой розетки 35-50 см, высота 20-26 см, листья цельные с черешком и лировидные. Сорта: Kousaitai (вр.к-956, Япония) и K-9708127 (вр.к-1301, Китай).

Листовая репа в Юго-восточной Азии используется для приготовления вторых блюд и засола, вкус свежих листьев чаще не такой приятно-капустный, как у капусты пекинской. Образцы листовой репы обычно имеют более-менее примитивный корнеплод, устойчивы к стеблеванию, часто двулетние. Хорошим капустным вкусом отличаются японские сорта Mustard Spinach (к-261) и Оосакина (оо - большой, саки - цветок, на - зеленый овощ, яп.) (вр.к-982) с крупной розеткой и широкими ланцетными листьями. Японская листовая репа Сиогацуна (к-526) имеет темно-зеленые нежные листья крупной розетки и развитый конический корнеплод, китайская репа Benmasijk Xiao baicai (вр.к-1129) имеет очень нежную крупную листовую розетку, похожую на пекинскую капусту сортотипа Дацинкоу, и развитый беловатый ширококонический корнеплод массой до 200 г.

В коллекции находятся красноокрашенные образцы листовых капустных культур: голландские образцы листовой репы Red Komatsuna (вр.к-1359) с фиолетовой окраской листьев, японской капусты вр.к-1360 с фиолетовозеленой окраской листовой пластинки и ярко-сиолетовыми черешками, американские образцы китайской капусты Purple Choi (вр.к-1407) и розеточной капусты Red Tatsoi (вр.к-1409) с красно-фиолетовыми листьями.

Часто интересные листовые/черешковые формы вида репа представляют собой естественные и искусственные гибриды между разновидностями и подвидами. Гибридизацию с листовой репой проводят для придания новому сорту устойчивости к раннему стеблеванию, что актуально, например, для капусты розеточной и китайской. Естественные гибридные формы распространены в Китае, Корее и Японии локально. Так, в Японии, прежде всего в районе Киото, существует большое разнообразие местных сортообразцов - стабильных гибридов между пекинской и китайской капустами, китайской и розеточной капустой и листовой репой, о чем писала еще Е.Н. Синская по результатам экспедиции в Японию в
1928 г. (4). Среди новых поступлений в коллекцию ВИР интересны устойчивые к стеблеванию гибрид китайской капусты и листовой репы Харуми (к-431, Япония), гибрид листовой репы и розеточной капусты Саори Комацуна (к527, Япония) и гибрид китайской и ноздреватой капусты вр.к-1088 (Китай).

В коллекции ВИР находятся образцы итальянской культуры брокколетто, которая также относится к виду Brassica rapa. Продуктовый орган - головка, сходная с головкой брокколи вида капуста огородная. Часто итальянские фермеры возделывают популяции, включающие и брокколи, и брокколетто, не скрещивающиеся между собой. Среди образцов брокколетто коллекции есть переходящие к стеблеванию в условиях Ленинградской области на 35-40-е сутки, и есть устойчивые к стеблеванию. Диаметр компактной или полураскидистой листовой розетки 30-50 см, листья лировидные на черешках длиной 7-16 см, листовая пластинка усеченно-овальная длиной 10-20 см, шириной 8-18 см, ярко-зеленая и яркотемно-зеленая, опушение чаще отсутствует, но у отдельных образцов варьирует от отсутствия до сильного. Головка рыхлая и среднеплотная, диаметром 4-8 см, массой 50-150 г, масса листовой розетки 0,2-0,8 кг.

Среди изученных культур выделены образцы с ценным биохимическим составом листьев (табл. 3).

Таким образом, в коллекции ВИР находится широкое разнообразие капустных культур вида репа, которые могут быть использованы для увеличения ассортимента возделываемых в России овощей.

\section{Литература}

1. Артемьева A.M. Доноры и источники для селекции листовых овощных культур вида Brassica rapa L. (Пекинская, китайская и японская капусты, листовая репа). Каталог мировой коллекции ВИР. СПб. 2004. Вып. 740. - 132 с.

2. Государственный реестр селекционных достижений, допущенных к использованию (на 26.01.2017 г). - М., 2017. - 468 с

3. Игнатов А.Н., Артемьева А.М., Чесноков Ю.В., Политыко В.А., Матвеева Е.В., Ораевский А.А., Шаад Н.В. Устойчивость к возбудителю сосудистого бактериоза и листовой пятнистости у Brassica rapa L. и B. napus L. / Сельскохозяйственная биология. 2011. - T.1. - C. 85-92.

4. Синская Е.Н. Краткий очерк сельскохозяйственного растениеводства в Японии (по данным поездки в Японию в 1928 г.) / Тр. по прикл. ботан., генет. и селекции. 1930. Т. 22. Вып. 5.- С. 217-283. 